\title{
TRISTRAM HOOLEY
}

\section{PINING FOR THE FJORDS}

\author{
International Perceptions of Nordic Work, Education and Career Guidance
}

\begin{abstract}
This chapter explores the way in which Nordic work, education and career guidance are seen by those outside of the Nordic region. It draws on an online survey of international informants which gathered respondents' opinions about the Nordic countries. It finds that respondents are overwhelmingly positive about the Nordic countries, even though they do not claim to be particularly informed about these countries. They report that on average the Nordic countries are better places to work, study and receive career guidance than their own countries. The chapter makes the argument that the way that the brand of 'Nordicity' has been disseminated internationally can account for at least some of this international perception. While the 'Nordic' has become a powerful and positive signifier, it is an ambiguous one onto which the international community can project their own meanings and use to serve their own political ends.
\end{abstract}

\section{INTRODUCTION}

I write this chapter as an admiring interloper into the Nordic world. Born in England, I did not visit a Nordic country until I was around 40 years old. However, before I ever set foot in a Nordic country I had formed a strong sense of the region. This was influenced by the regions' popular culture (from the Nordic noir that has come to dominate television and literature to music ranging from Abba to Norwegian black metal) and material culture (from knitwear to Nokia to Ikea and Volvo). It was also influenced by my knowledge of the politics of the countries, the Nordic welfare model and, as an educational researcher, my awareness of the 'world leading' Nordic education system, and particularly the Finnish 'miracle' of outstanding performance in the Programme for International Student Assessment (PISA) (Simola, 2005). In my imagination the Nordic served as a utopian other which at once offered cultural richness and sophistication and a political and economic system inoculated against the worst excesses of neoliberalism.

My naïve enthusiasm for the Nordic countries remains largely intact, although it has been somewhat tempered as I have become more informed over the last five years. During this time, I have begun to travel and work more and more in the 
region. I remain an outsider in these societies, hamstrung by my monolingualism, but frequent visits to the region, employment at a Norwegian university and the regular need to engage with the Nordic brand of organisational and state bureaucracy has increased my insights into the culture and operation of these countries. I am also blessed to be able to call on the insights of an array of Nordic friends and colleagues who have helped me to understand and decode my experiences.

This chapter focuses on how those living beyond the Nordic region perceive the region in relation to work, learning and career guidance. It explores how career guidance within the countries is seen, but also how the wider educational and employment system is perceived. In many ways it can be viewed as an attempt to figure out if my perspectives on the Nordic countries are shared by others.

\section{DEFINING THE NORDIC AND NORDICITY}

The Introduction to this volume made the argument that 'the Nordic' is a complex category which it is important to interrogate when exploring social and political phenomenon within the Nordic states. 'The Nordic' concept has geographical, historical, cultural, political and ideological components and inevitably with such a complex category there is disagreement about what it means (see Haug, Hooley, Kettunen, \& Thomsen, Chapter 1, this volume; Bakke, Chapter 2, this volume). The process of contesting the meaning of the concept of 'the Nordic' or 'Nordicity' has considerable implications. Petersen (2011, p. 47) talks about a 'Nordic epistemic community' which shares a common set of starting points for discussion and debates about the nature and future of the Nordic region. Within the Nordic countries arguments about what constitutes the 'Nordic model' are an important site on which political debate is conducted (Ryner, 2007). Nordicity also serves as a justification for close collaboration between the Nordic states and frames the nature of that collaboration and the way in which it can be negotiated and changed (Strang, 2015).

This chapter is going to move away from considering the Nordic as an internal category within the Nordic states and explore what it means externally to those outside of the region. The Nordic states are globally important as models for public policy and culture. Some writers have argued that the development and propagation of the idea of 'Nordic exceptionalism', the idea that the Nordic states are better than other states and that they offer a model which other states should follow, has been a conscious strategy of branding, communication and the exercise of soft power by the Nordic states (Andersen, Kjeldgaard, Lindberg, \& Östberg, 2019; Browning, 2007; Marklund, 2017).

For outsiders to the region, Nordicity has become an appealing idea (Ekstrand, 2018). It suggests much, but is often light on specifics. Andersen et al.'s (2019, p. 214) characterisation of Nordicity as a 'complex brandscape' is helpful as it shows how multiple, and often contradictory, concepts, both political and cultural are associated with the signifier of the Nordic. 
Despite the complex array of meanings associated with 'the Nordic' it continues to exert a powerful influence on politics and public policy outside of the Nordic countries (Jakobsen, 2009; Marklund, 2017; Witoszek \& Midttun, 2018). This is true in a variety of spheres, but for the purpose of this chapter it is worth noting the fact that other countries are often drawn to borrow policies and practices from Nordic counties in the field of education (Cardona López, Nordfjell, Gaini, \& Heikkinen, 2018; Chung, 2016; Teresevičienė, Trepulè, \& Trečiokienė, 2018). For example, on the Department for Education (DfE) website in England, Finland is the third most commonly mentioned European Union (EU) or Organisation for Economic Co-operation and Development (OECD) country (total 41 countries). ${ }^{1}$ Sweden is the 11 th, Norway and Denmark the 15 th and 16th and Iceland the 20th. Taken together the Nordic countries comprise $18 \%$ of all EU and OECD references made on the DfE website.

In summary, this study is framed by the international appeal of the Nordic. This appeal is personal to the author but has also been observed far more widely by commentators on marketing and branding and on politics, public policy and ideology. Within the field of education, the Nordic 'brand' is an important influence on international policy and practice. The study builds on this literature to explore whether such Nordophillia also extends to international perspectives on Nordic career and career guidance.

\section{ABOUT THE STUDY}

To explore the issues already discussed relating to the perceptions of Nordic countries and the pervasiveness of Nordicity I conducted an online survey which examined how people outside of the Nordic countries perceived work, the education system and career guidance within the Nordic countries.

The study explores the perspectives of people living outside of the Nordic countries. As will be seen, most of the participants had very limited engagement with the Nordic countries and often had unreliable perceptions about what the situation was within these countries. The purpose of this study is to explore and describe these external perspectives rather than to judge their accuracy. The rest of this book provides extensive insights into career and career guidance in the Nordic countries. This chapter seeks to capture how the Nordic career guidance systems are perceived from a distance and through the distorting prism of international representations of Nordicity.

I developed the survey in Microsoft Word and sought initial feedback from three Nordic experts in career guidance. Following this I revised the survey and put it into Snap Survey. ${ }^{2}$ I then trialled a pilot version of the survey with two careers professionals and three researchers. I then revised the survey and sent it out for further review. This time I received feedback from four careers professionals, one teacher and one researcher. 
The survey was then launched and left open between November 2018 and March 2019. Responses were collected from participants in online fora associated with career and career guidance and through an email and social media campaign by the author. In total 300 responses were gathered.

I cleaned the data to remove responses with a substantial amount of missing data, those where respondents had not given permission for their data to be used and any test responses. I also removed 33 responses that were submitted by respondents from the Nordic countries. This resulted in a total of 184 valid responses from respondents in non-Nordic countries.

Responses were received from a total of 27 countries. However, most countries only submitted a small number of responses. For analytical purposes the sample was divided into four categories (UK, US \& Canada, EU (non-UK) and others). The sample was dominated by responses from the UK as can be seen in Table 3.1.

Table 3.1. Responses by country

\begin{tabular}{lc}
\hline Country & Number of responses \\
\hline UK & 114 \\
EU (non-UK and non-Nordic) & 34 \\
US \& Canada & 19 \\
Others & 12 \\
\hline
\end{tabular}

Respondents were generally highly qualified with $71 \%$ having a postgraduate degree or higher. Around half (52\%) described themselves as careers professionals with another quarter (28\%) saying that they were not career professionals but did help others with their career in their work. I have explored the variation in results by country and profession and although there are some differences, the limited sample sizes make it difficult to draw any robust conclusions about whether country or profession are driving how positive respondents are about the Nordic countries. However, it would be valuable to retain these questions if the survey was repeated with a larger sample. Were I to repeat the survey I would also add an additional demographic question asking about participants' political orientation as I hypothesise this might be a significant factor.

The nature and size of the sample means that no claim can be made for the wider representativeness of these findings. It would be possible to repeat this with other samples and to find very different results. However, the results are both interesting and provide evidence of clear patterns. Given this, they are worthy of discussion and I would be keen to repeat the survey, or to have others do so with more precisely specified and representative samples.

The survey began with a section asking participants how engaged they were with the Nordic countries. It asked them whether they had read about any of the 
countries, visited them, visited them for work or study or lived in them. They were also asked for their proficiency in any of the Nordic languages. They rated their language proficiency on a four-point scale: not at all (0); not well (1); well (2); or very well (3).

Respondents were then asked a series of questions about what it would be like to work, study or access career guidance in the Nordic countries. They were offered the same five point scale for each area with the following options: is much better than in my country (5); is a little better than in my country (4); is about the same as in my country (3); is a little worse than in my country (2); is much worse than in my country (1).

The data contained four open ended qualitative questions. These were as follows:

- What is the best thing you've heard or seen about career guidance in the Nordic countries? (67 responses)

- What is the worst thing you've heard or seen about career guidance in the Nordic countries? (41 responses)

- Do you have any other impressions of Nordic career guidance that you would like to share? (40 responses)

- Any other comments? (30 responses)

These data were analysed together using content analysis (Stemler, 2001) and inductively coded in Excel. A code book was created which comprised of seven main themes, each with a series of sub-themes: values (5 sub-themes); the state (4); work (6); education (5); career guidance (7); professionalism (5); and migrants (3).

\section{RESULTS}

\section{Engagement}

The average participant reported that they had read about two Nordic countries (average 2.26 countries) and visited one Nordic country (1.20). They were unlikely to have visited any of the Nordic countries for work $(0.35)$ or study $(0.05)$ or to have had a job (0.05) in any of these countries.

Respondents' Nordic language skills were generally very weak with the average score for each of the languages as follows: Danish ( 0.05 on a scale from 0 to 3$)$; Finnish (0.04); Icelandic (0.03); Norwegian (0.08); and Swedish (0.11). At least $90 \%$ of the respondents reported that they had no language skills at all in each of the languages.

The questions around engagement in Nordic countries and languages were then summed to create a single score summarising Nordic engagement. This was then transformed into a score between 1-100. In order to score the maximum score of 100 respondents would have had to have lived and worked in all of the Nordic countries and speak all of the Nordic languages very well. Respondents were all in the lower half of the potential engagement score, with scores ranging between 0 and 50 with a mean of 10.64 . In summary then, the majority of the sample reported very limited 
engagement with the Nordic countries and almost none had a substantial engagement with the countries on which they were offering their opinions.

The lack of clear experience of the Nordic countries did not mean that respondents had nothing to draw on when rating the region. However, in some cases while the sources of information used may have been enough to provide a general impression of the country, they offered limited insights about the details of education and employment policy. One example is offered by the following comment:

My first impressions come from watching Borgen on TV which portrays an equal, fair society full of well-educated professionals. I also have a Swedish female friend who is strongly focused on her career and against any gender stereotypes.

Results from the survey must be understood in this context. Respondents are generally working from a limited base of information and experiences about the Nordic countries. Consequently, many judgements should be viewed as a best guess by respondents about what the system in the Nordic countries is likely to be like rather than based on clear evidence. Such impressionistic responses are useful in judging how Nordic career and career guidance is seen internationally by nonspecialists in the region.

\section{Work}

Respondents were asked a series of questions about what it would be like to work in the Nordic countries. The questions addressed standard of living, work-life balance, unemployment benefits, trade union membership and equality and diversity. Table 3.2 sets out the mean responses that respondents gave to these questions.

Table 3.2. Mean responses to questions about work $(1=$ much worse than in my country/ $3=$ about the same as in my country/ $5=$ much better than in my country)

\begin{tabular}{lc}
\hline In the Nordic countries my chance of & Mean response \\
\hline Having a good standard of living & 4.47 \\
Having a good working life & 4.27 \\
Being well paid & 4.10 \\
Being able to find good work as a woman & 4.08 \\
Being able to access good benefits if I was out of work & 4.07 \\
Joining a trade union that is recognised by my employer & 3.74 \\
Being successful in self-employment & 3.45 \\
Finding a job & 3.42 \\
Being able to find good work as an immigrant & 3.42 \\
\hline
\end{tabular}


Taken together it is noticeable that on average respondents reported that working life in the Nordic countries is better in every sense than their own countries. They believed that Nordic countries are better places to live and work in for everyone. It is important to stress that these perspectives are subjective and not necessarily based on clear evidence. Various mechanisms exist to make more objective, albeit still contestable, judgements on the relative quality of life, work, education and career guidance in the Nordic countries and how they compare to the rest of the world e.g. the OECD's Better Life Index. ${ }^{3}$ The purpose of this chapter is to capture subjective perceptions rather than to assess them against more objective measures.

The quantitative data was further illuminated by the responses to the qualitative questions. Data that addressed work was coded to the following codes: decent work (4 responses); workplace career development (3); low unemployment (2); family friendly (1); precarity (1); and over qualification (1). In general, this backed up the findings of the quantitative data.

It seems that there is a priority for personal development and happiness along with career progression e.g. work/life balance.

Striving to keep employees happy and healthy regardless of position within the company. Making the place of work a comfortable and happy environment.

I am also of the impression that employers take a more active role in employee development and engagement than in the UK. As I understand that in Sweden, employee representation in company management structures is well-embedded and follows the approach indicated by organisations like the ILO. Employers are also active in secondary school management structures (I understand).

Although there were some dissenting voices which suggested that 'many people are over-qualified for the jobs available' and raised the issue of 'temporary contracts' and 'redundancy' these were generally running against a depiction of Nordic working life as both financially lucrative and respectful of a good work life balance.

There was some limited discussion of the idea that this level of access to the good life might not always be extended to the migrant populations within the Nordic countries. Respondents discussed what support existed for this population (6) with one noting that ' $I$ understand there are challenges in meeting the needs of immigrant populations' while another had heard more positive feedback, 'I have heard positive reports about research programmes focusing on how career practitioners can support refugees'. Other respondents noted that migrants faced discrimination and racism (2) with one reporting that, 'I heard a Radio 4 programme criticising integration of Muslim groups in Sweden'. Others highlighted the challenges of various language issues (2). However, given the current importance of migration issues to Nordic politics (Loftsdóttir \& Jensen, 2016), they were only raised by a small minority of observers, with $46 \%$ feeling that the Nordic countries were better place to work as a migrant than their own country and only $17 \%$ feeling that they were worse. 


\section{Learning}

Respondents also answered questions on whether they felt that the Nordic countries were a better place to learn in than their own countries. These questions address the quality of education, the experience of being in education and the quality of vocational and higher education. Table 3.3 sets out the mean responses that they gave to these questions.

Table 3.3. Mean responses to questions about learning $(1=$ much worse than in my country/ $3=$ about the same as in my country/ $5=$ much better than in my country)

\begin{tabular}{lc}
\hline In the Nordic countries my chance of & Mean response \\
\hline Getting a good education & 4.18 \\
Enjoying my time in education & 4.12 \\
Getting good vocational and technical education & 4.03 \\
Going to a good university & 3.74 \\
\hline
\end{tabular}

Just as with work, respondents reported that on average they felt that every aspect of education, that they were questioned about, was better in the Nordic states than it was in their countries.

Again, the qualitative data provides further illumination as to why they felt this way. Respondents reported that the education system in the Nordic countries was learner centred (5); that there was a strong education system (3) which included a commitment to both early years provision (2) and lifelong learning (3). Some also argued that it was well aligned with the employment system, saying 'I am also of the impression that employers take a more active role in employee development and engagement than in the UK'. The following two quotes provide good examples of how the Nordic education systems are seen by respondents and how they believe that career guidance is integrated into these systems.

My impression of Nordic countries is that overall, education is more concerned with well-being and 'holistic' development than in the UK, and much less target-driven. Career guidance in these countries may reflect a more student/ person centred approach, and a more consistent linkage between education with eventual work life.

The Finnish education system has been praised for being exemplary I believe, so I would think that this might include their careers guidance services to pupils. I think the system is less academic focused so perhaps the emphasis on developing students' emotional wellbeing would include guidance counselling.

The idea of a 'holistic', 'learner centred' system which is attentive to the wellbeing of the individual learner rather than being metric driven perhaps explains why 
people were convinced that not only would they get a better education, they would also enjoy themselves more whilst in education.

\section{Career Guidance}

Finally, I asked respondents to reflect on how career guidance in their countries compared to that in the Nordic countries. These questions addressed access to career guidance and the professionalism of the career guidance workforce. Table 3.4 sets out the mean responses that they gave to these questions.

Table 3.4. Mean responses to questions about career guidance $(1=$ much worse than in my country/ $3=$ about the same as in my country/ $5=$ much better than in my country)

In the Nordic countries my chance of Mean response

Getting good career guidance while I'm in the education system 3.97

Getting good career guidance during periods of unemployment

As with the other categories the perception of Nordic career guidance is overwhelmingly positive, albeit a little less resoundingly so than some of the better scoring elements of the work and learning dimensions. On average respondents believe that in the Nordic countries they are more likely to get good career guidance in education, employment and during periods of unemployment. They also believe that this is more likely to be given by a qualified professional. Once again it is worth stressing the fact that the picture of Nordic career guidance described in this chapter does not necessarily align with the reality. It is based on international perceptions of the situation that are often based on very limited actual engagement with Nordic career guidance.

The qualitative data provides further illumination about respondents' understanding of career guidance in the Nordic countries. A large proportion of the qualitative comments (22 in total) were focused on the issue of gaining access to career guidance. In general, these comments about access were positive, for example 'I think that there is a much greater focus on the whole society and ensuring that everyone can access quality guidance at all stages of their career'. However, there were also a minority who raised concerns about access e.g. highlighting limited provision in higher education or raising concerns about accessing career guidance in the more rural and remote areas of the Nordic region.

Career guidance in the Nordic region was viewed as being well established (8), and strongly embedded in the education system (12), one respondent praised 'the way in which careers guidance is incorporated into the education system. It is taught from an early age and feels like it's embedded as a principle of lifelong learning'. 
Respondents also reported that Nordic career guidance was highly professionalised. Noting that staff were likely to be appropriately trained and qualified (15) and that services were likely to be delivered in a professional way (6). Some also noted that that working within the profession conferred high status (8) and good pay and conditions (2). As one respondent summarised:

I think it's astounding, how Norway is currently setting up a guidance system based on specialised training for career counsellors and high-quality standards. My impression from the other countries, especially Sweden, Denmark and Finland is that career services are relatively well funded, and that professionals have good training and are interested in continuous further education and quality development.

Career guidance in the Nordic countries is also seen to be innovative (10), with several respondents commenting on e-guidance and on innovations in community focused guidance. It was also viewed as being underpinned by a strong evidence base (7) and built on a humanistic and person-centred ethos (7).

Nordic career guidance appears to be a reflection of a 'Nordic way of life' rather than a distinct set of policies and procedures. My impression of Nordic career guidance therefore is that it is individual needs-based, but that individuals are seen as part of their communities and social networks. This appears to contrast with the more individualised, competitive paradigm that underlies career guidance in the UK and North America.

The idea that Nordic career guidance is underpinned by different values from that found in the English speaking world is an interesting idea which aligns to some extent with thinking that is found across the Nordic countries (as described in the 'four COs' set out by Haug et al., Chapter 1, this volume). The data suggests that this difference is perceived by some respondents from outside of the country and generally viewed positively.

\section{Broader Understandings of the Nordic Counties}

The qualitative data provides us with further context to this overwhelmingly positive understanding of career and career guidance in the Nordic states. Away from the specifics of education and employment policy the region was seen as being egalitarian (5), committed to the wellbeing of its citizens (4), and characterised by fairness (3) and a social democratic political consensus (3).

My image of Nordic countries is a society where social inequalities as regards to gender, socioeconomic status, and origin are weaker than elsewhere in the world. Career guidance is part of this socially performant system and therefore inspiring. 
This is sometimes contrasted with respondents' own context for the purpose of critique. As one respondent describes it 'they [the Nordic states] are more egalitarian than Great Britain. Great Britain is still riddled with snobbery', while another argues that it is different political parties and ideologies that account for the fact that the Nordic countries are better places to live and work in; 'the key to their success seems to be a lack of Tories in the Nordic countries'.

Policy in the Nordic states is seen as being committed to the welfare state (3) and underpinned by forms of social partnership (3). This means that there is a commitment to funding public services, including career guidance, well (14) and that there is strong public policy support for career guidance (12). Such support for career guidance is seen as being part of the Nordic welfare state and as something that is, as one respondent noted, 'closely linked to government strategy'.

\section{DISCUSSION}

The findings suggest that those outside of the Nordic countries (at least as far as this can be inferred from my sample) are overwhelmingly positive about work, learning and career guidance within the Nordic countries. The Nordic is viewed as a utopian other where the problems faced in domestic policy and practice have been solved. People live happy lives, get paid well and enjoy good work/life balance. Education is widely available and built on humanistic values that respondents feel are absent from their own system. Career guidance is widely available and delivered by well qualified, well respected and well-paid professionals. Things are perceived as being better in the Nordic countries, and as 'exceptional'.

I began this chapter by confessing to be a fan of all things Nordic, but I'm not blind to its faults and limitations. There are no shortage of people who are keen to write about the 'dark side of the Nordic model' and highlight the less frequently noticed traditions of authoritarianism and ethno-nationalism that can be found within Nordic culture (Cocozza \& Hort, 2011; Keskinen, Tuori, Irni, \& Mulinari, 2016; Ugelvik, 2011). Even for those who are enamoured with the 'Nordic model' there are deep concerns that this model is under-attack from both neoliberalism and the rise of the populist right as well as questions about whether the model still endures (Arnesen \& Lundahl, 2006; Bergholm \& Bieler, 2013; Kvist \& Greve, 2011). Finally, as this book shows, the practice of career guidance in the Nordic countries is complex and contested, with policy support for services and professionalism often waxing and waning as in other countries.

None of these criticisms or qualifications undermine the value of looking to career guidance in the Nordic countries. There is, as this volume shows, much in the region than other countries can learn from. However, the presumption of 'Nordic exceptionalism' without a clear understanding of the context and subtleties of policies and practices in these countries is of limited use for those seeking to borrow policies and practices. 
The perception that respondents in this study have of education, employment and career guidance in the Nordic countries can be viewed in many ways as a Derridean signifier which has become untethered from any meaningful centre (Derrida, 1970). The current volume is intended to address this by providing a detailed and critical account of practice in the Nordic countries. However, at present participants are more likely to be engaged in free play with the terminology of the Nordic and the ideas that it suggests without being able to lock these ideas onto any empirical facts.

The overt international self-branding efforts pursued by Nordic states since at least the 1950s began the process of, narrowing the concept of Nordicity until it came to signify a superficial version of the politics and culture of these societies (Marklund, 2017). More recent battles between centre left and centre right parties over the legal right to associate themselves with the, now trademarked, concept of the 'Nordic model' have extended this. The Nordic is something that everyone wants to own, but meaning is deferred down a chain of signifiers which stretch out past social democracy, skiing and Borgen on into the far north where they become increasingly indistinct.

Actors in other countries then, can seize on these Nordic signifiers in ways that are meaningful to them and which serve their ends. The Nordic signifier confers power far more than it confers meaning and so it is turned to political ends. The respondents in my survey are keen to use the Nordic to highlight the limitations of the policy and cultural context in which their practice operates.

\section{CONCLUSIONS}

The Nordic exerts a powerful influence on the popular imagination outside of the Nordic countries. This influence goes well beyond the focus of this book, but is also keenly felt with respect to education and employment policy in general and career guidance in particular.

In general, the Nordic is viewed positively with respondents to the survey arguing that work, learning and career guidance are all better in the Nordic. However, the brand of 'Nordicity' is a loosely defined signifier which is often associated with chains of other signifiers (e.g. modernity, social democracy, the welfare state, and good design) which can also be difficult to define. Respondents were not relaying their experience of the particularity of any Nordic countries that they had visited or studied, rather they were wielding the signifier of 'Nordicity' as part of a utopian imagination of a 'better place' and an implied critique of their own context.

Given the importance of the Nordic as an international signifier in career guidance policy and practice, the work collected together in the current volume is of critical importance. If this can enrich wider understanding of how career guidance is practiced within the Nordic countries, it might also have the effect of strengthening the quality of debate about the value and practice of career guidance in other parts of the world. 


\section{NOTES}

1 Department for Education website is available at https://www.gov.uk/government/organisations/ department-for-education. The analysis was conducted on the 20th May 2019 and used the 'advanced search option to specified 'Department for Education within the organisation box. All EU and OECD were searched for.

2 Snap Survey is a commercial survey tool. Further information about the tool is available at https://www.snapsurveys.com/

3 The OECD Better Life Index is available at http://www.oecdbetterlifeindex.org

\section{REFERENCES}

Andersen, L. P., Kjeldgaard, D., Lindberg, F., \& Östberg, J. (2019). Nordic branding: An odyssey into the Nordic myth market. In S. Askegaard \& J. Östberg (Eds.), Nordic consumer culture (pp. 213-238). Cham: Palgrave Macmillan.

Arnesen, A. L., \& Lundahl, L. (2006). Still social and democratic? Inclusive education policies in the Nordic welfare states. Scandinavian Journal of Educational Research, 50(3), 285-300. doi:10.1080/00313830600743316

Bergholm, T., \& Bieler, A. (2013). Globalization and the erosion of the Nordic model: A Swedish-Finnish comparison. European Journal of Industrial Relations, 19(1), 55-70. doi:10.1177/0959680112474747

Browning, C. S. (2007). Branding Nordicity: Models, identity and the decline of exceptionalism. Cooperation and Conflict, 42(1), 27-51. doi:10.1177/0010836707073475

Cardona López, J. A., Nordfjell, O. B., Gaini, F., \& Heikkinen, M. (2018). Promising Nordic practices in gender equality promotion: Developing teacher education dialogue, practice, and policy cycles online. Policy Futures in Education, 16(5), 605-619. doi:10.1177/1478210317722286

Chung, J. (2016). The (mis) use of the Finnish teacher education model: 'Policy-based evidence-making'? Educational Research, 58, 207-219. doi:10.1080/00131881.2016.1167485

Cocozza, M., \& Hort, S. (2011). The dark side of the universal welfare state? Child abuse and protection in Sweden. In N. Gilbert, N. Parton, \& M. Skivens (Eds.), Child protection systems: International trends and orientations (pp. 89-111). Oxford: Oxford University Press. doi:10.1093/acprof:oso/ 9780199793358.003.0005

Derrida, J. (1970). Structure, sign, and play in the discourse of the human sciences. Retrieved http://www2.csudh.edu/ccauthen/576f13/drrdassp.pdf

Ekstrand, S. (2018). Scandi Chic or Nordic Noir - The value of the Nordic brand and the effect of consumer affinity and stereotypes on behaviour among international consumers. Oslo: BI Norwegian Business School.

Jakobsen, P. V. (2009). Small states, big influence: The overlooked Nordic influence on the civilian ESDP. Journal of Common Market Studies, 47(1), 81-102. doi:10.1111/j.1468-5965.2008.01833.x

Keskinen, S., Tuori, S., Irni, S., \& Mulinari, D. (Eds.). (2016). Complying with colonialism: Gender, race and ethnicity in the Nordic region. London: Routledge.

Kvist, J., \& Greve, B. (2011). Has the Nordic welfare model been transformed? Social Policy \& Administration, 45(2), 146-160. doi:10.1111/j.1467-9515.2010.00761.x

Loftsdóttir, K., \& Jensen, L. (Eds.). (2016). Whiteness and postcolonialism in the Nordic region: Exceptionalism, migrant others and national identities. London: Routledge.

Marklund, C. (2017). The Nordic model on the global market of ideas: The welfare state as Scandinavia's best brand. Geopolitics, 22, 623-639. doi:10.1080/14650045.2016.1251906

Petersen, K. (2011). National, Nordic and trans-Nordic: Transnational perspectives on the history of the Nordic welfare states. In P. Kettunen \& K. Petersen (Eds.), Beyond welfare state models: Transnational historical perspectives on social policy (pp. 41-64), Cheltenham: Edward Elgar. doi:10.4337/9781849809603.00009

Ryner, J. M. (2007). The Nordic model: Does it exist? Can it survive? New Political Economy, 12(1), 61-70. doi:10.1080/13563460601068644 


\section{T. HOOLEY}

Simola, H. (2005). The Finnish miracle of PISA: Historical and sociological remarks on teaching and teacher education. Comparative Education, 41(4), 455-470. doi:10.1080/03050060500317810

Stemler, S. (2001). An overview of content analysis. Practical Assessment, Research \& Evaluation, $7(17), 137-146$.

Strang, J. (Ed.). (2015). Nordic cooperation: A European region in transition. London: Routledge.

Teresevičienè, M., Trepulè, E., \& Trečiokienè, E. (2018). The impact of Nordic adult education ideas on the development of a democratic society in Lithuania. International Review of Education, 64(4), 443-463.

Ugelvik, T. (2011). The dark side of a culture of equality: Reimagining communities in a Norwegian remand prison. In T. Ugelvik \& J. Dullum (Eds.), Penal exceptionalism? (pp. 133-150). London: Routledge.

Witoszek, N., \& Midttun, A. (Eds.). (2018). Sustainable modernity. The Nordic model and beyond. London: Routledge. 